\title{
IMPLEMENTASI MODEL KOMUNIKASI BISNIS FRANKOFON DALAM PEMBELAJARAN FRANCAIS DE LA COMMUNICATION PROFESSIONNELLE
}

\author{
Yadi Mulyadi, Dudung Gumilar, Iis Sopiawati \\ Jurusan Pendidikan Bahasa Perancis FPBS UPI \\ Korespondensi: Jl. Dr. Setiabudhi No. 229 Bandung 40154 \\ Pos-el: yadimulyadi825@yahoo.fr
}

\begin{abstract}
Abstrak
Penelitian ini bertujuan untuk memperoleh data perihal (1) efektivitas penggunaan model pembelajaran Komunikasi Bisnis Frankofon dalam meningkatkan kemampuan mahasiswa terhadap bahasa Perancis komunikasi profesional, (2) kontribusi model tersebut dalam pembelajaran bahasa Perancis bisnis, (3) kelebihan dan kekurangan model komunikasi bisnis frankofon dalam pembelajaran Français de la communication professionnelle. Hasil penelitian menunjukkan bahwa model yang diteliti terbukti efektif dalam meningkatkan kualitas pembelajaran Français de la communication professionnelle (PR308) juga telah membantu mahasiswa terkait pemahaman konsep-konsep berupa bahasa Perancis bidang profesi dan bisnis yang kelak akan dibutuhkan di dunia kerja yang nyata.
\end{abstract}

Kata-kata kunci: Model komunikasi bisnis frankofon, bahasa Perancis untuk tujuan khusus

\begin{abstract}
The aims of this research are to find out (1) the effectiveness of the use of French for business communication model and to develop students skills in French for special purposes (2) the contribution of the model analysed in teaching French for special purposes, namely, Français de la communication professionnelle (3) the advantages and the disadvantages of the model analysed in the teaching of Français de la communication professionnelle. The data analyzed demonstrates that the model analysed was effective and improved the quality of leaning French for special purposes, and the model helped the students to understand the concepts of French for professionals and business. For the students, this model helped to master not only French language skills but also the professionals and the business materials in real world.
\end{abstract}

Keywords: French business communication model, French as special purposes

\section{PENDAHULUAN}

Sesuai dengan tujuan Jurusan Pendidikan Bahasa Perancis FPBS UPI yang merujuk pada Misi dan Visi Fakultas dan Universitas Pendidikan Indonesia, bahwa di samping menyelenggarakan pendidikan untuk calon pendidik dan tenaga kependidikan dalam bidang kebahasaan, kebudayaan dan kesusastraan Perancis sesuai dengan tuntutan dan kebutuhan masyarakat/ pasar kerja, juga mendidik calon tenaga ahli dan tenaga profesional non-kependidikan dalam bidang bahasa Perancis untuk Tujuan Khusus (Français sur Objectifs Spécifiques) atau lebih dikenal dengan istilah FOS, dan dalam bidang penerjemahan.

Berdasarkan pada tujuan tersebut di atas, jurusan berupaya untuk mengembangkan berbagai model pembelajaran guna meningkatkan kualitas 
pembelajaran dan berupaya untuk meningkatkan mutu proses belajar mengajar melalui penerapan model-model pembelajaran yang inovatif dan produktif yang didasarkan pada hasil penelitian guna menyiapkan calon lulusannya agar siap menghadapi pasar kerja di luar jalur kependidikan yang semakin kompetitif.

Dalam upaya menyiapkan calon lulusannya untuk menjadi tenaga ahli dan tenaga profesional di bidang non kependidikan, sesuai dengan kurikulum UPI tahun 2006, pada Jurusan Pendidikan Bahasa Perancis terdapat empat mata kuliah bahasa Perancis untuk Tujuan Khusus (FOS) yang termasuk dalam kelompok Mata Kuliah Pendalaman dan Perluasan (MKPP) di antaranya bahasa Perancis pariwisata (Français $d u$ Tourisme), bahasa Perancis komunikasi profesional (Français de la Communication Professionnelle), bahasa Perancis bisnis (Français des Affaires) dan bahasa Perancis Multimedia (Français des Médias).

Zabardi (2004:42) mengungkapkan bahwa "tujuan utama dari pembelajaran FOS adalah agar pembelajar dan pengajar mampu berkomunikasi dalam dunia profesi dengan mitra frankofon (penutur bahasa Perancis)". Tentu saja kemampuan berkomunikasi tersebut dilandasi dengan pengenalan terhadap budaya komunikasi bahasa dan budaya sasaran yaitu bahasa dan budaya Perancis. Penjelasan tersebut menggambarkan bahwa pembelajaran FOS diselenggarakan dengan tujuan untuk menjawab tuntutan kebutuhan pembelajar dan pengajar bahasa Perancis di dunia kerja terkait bahasa dan budaya dalam berkomunikasi melalui bahasa Perancis bidang khusus yaitu bidang bisnis, ekonomi, kedokteran, teknik, pariwisata dan perhotelan, sosial, dan lain-lain.

Selanjutnya Zabardi (ibid) menambahkan bahwa "tidak hanya pembelajar bahasa Perancis sebagai bahasa asing (FLE) yang sudah menempuh waktu belajar selama 120-150 jam yang dapat mempelajari FOS, tetapi juga pembelajar bahasa Perancis tingkat pemula pun dapat mulai langsung mempelajarinya sejak awal pertemuan". Pernyataan tersebut didasari oleh adanya berbagai buku pegangan yang telah diterbitkan oleh penerbit di Perancis untuk dijadikan panduan bagi pengajar dan pembelajar FLE untuk mempelajari FOS, di antaranya buku Tourisme.com dapat digunakan untuk mempelajari bahasa Perancis bidang Pariwisata, buku Français de l'Hôtellerie et de la Restauration untuk bidang perhotelan dan restorasi, buku $A$ grande vitesse dan buku Français $d u$ monde du travail untuk bidang komunikasi profesional umum, buku Affaires.com untuk bidang bahasa Perancis bisnis, dan buku pegangan lainnya.

Sekaitan dengan hal di atas, Hutchinson dan Waters dalam Hardini (2002:42-43) menyatakan bahwa "pembelajaran bahasa tidak hanya berkaitan dengan pengetahuan kebahasaan. Permasalahan yang paling dasar dari pembelajaran bahasa kedua merupakan perbandingan antara kemampuan konseptual dan kognitif dan tingkat kebahasaannya". Dalam pemerolehan bahasa kedua, kemampuan tersebut berbeda satu sama lain. Bagi yang mempelajari bahasa Perancis sebagai bahasa asing, secara konseptual dan kognitif mungkin dianggap mampu, tetapi dari segi kebahasaannya masih lemah. Masalah ini muncul terutama dalam pembelajaran bahasa Perancis untuk Tujuan Khusus. Kemampuan seorang profesional yang memadai dalam bidangnya tanpa didukung oleh penguasaan bahasa yang cukup merupakan kendala yang sangat berarti untuk meningkatkan profesionalismenya.

Teori tersebut di atas mengisyaratkan bahwa untuk mempelajari bahasa Perancis untuk Tujuan Khusus (FOS) dibutuhkan keseimbangan antara pengetahuan konseptual dan kognitif dengan pengetahuan kebahasaan yang memadai. Selanjutnya Mangiante dan 
Parpette (2004:5) membedakan antara pembelajaran FOS dan FLE dilihat dari sudut pembelajar sebagai berikut :

a) Pembelajar di sekolah dasar atau menengah yang mengikuti pembelajaran ekstensif beberapa jam dalam seminggu selama beberapa tahun dengan program yang bersifat umum. Pembelajaran tersebut sama halnya dengan pelajaran lainnya seperti matematika atau geografi. Di Indonesia pembelajaran bahasa Perancis untuk Tujuan Khusus tidak diberikan di jenjang tersebut melainkan di universitas. Hanya saja beberapa SMK yang dalam kurikulumnya terdapat bahasa Perancis, memberikan pelajaran bahasa Perancis, itupun sebatas pengetahuan dasar. Selain itu, pembelajaran bahasa Perancis di sekolah menengah masih menitikberatkan pada kompetensi kebahasaannya.

b) Pembelajar profesional adalah pembelajar yang mengikuti pembelajaran atau penataran untuk meningkatkan kemampuan kebahasaan sebelum berada di tempat ia bekerja. Materi yang diberikan terhadap pembelajar profesional berupa bahasa Perancis untuk Tujuan Khusus dalam hal ini profesionalisme.

Dalam pembelajaran FOS, Eurin (1992:18) mengatakan bahwa terdapat beberapa faktor yang perlu diperhatikan yaitu: a) motivasi, keinginan, pekerjaan pembelajar; b) pengetahuan, energi, kualitas pengajar dalam pembelajaran; c) pemilihan sarana pendukung pembelajaran; d) jumlah jam pembelajaran yang cukup; e) keadaan sarana yang baik dan tempat yang memadai; f) penyesuaian jadwal dengan publik (pembelajar); g) pembelajar memiliki kemampuan kebahasaan dan bidang profesional yang memadai; h) penggunaan teknologi mutakhir, dan; i) penguasaan sistem evaluasi oleh pengajar. Kesembilan faktor tersebut di atas merupakan sebagian dari kunci sukses dalam menyajikan pengajaran bahasa Perancis untuk Tujuan Khusus (FOS).

Apabila melihat kenyataan di lapangan, banyak lulusan yang telah terserap di bidang kerja non kependidikan, yaitu oleh lembaga yang bergerak di bidang perekonomian, perbankan, bisnis, pariwisata dan perhotelan. Hal itu menjadikan masukan bagi jurusan bahwa kebutuhan pasar kerja terhadap lulusan Jurusan Pendidikan Bahasa Perancis semakin besar tidak hanya menjadi pendidik tetapi juga menjadi tenaga ahli profesional di luar profesi pendidik. Selain itu, maraknya perusahaan Perancis di Indonesia di antaranya: Total, Novotel, Ibis, Carrefour, Schlumberger, Alastom, menjadi peluang bagi calon lulusan untuk lebih menyiapkan diri dan terjun di bidang non-kependidikan.

Dengan merujuk pada fakta-fakta di atas, pasar kerja yang semakin kompetitif mengharuskan jurusan untuk lebih menyiapkan calon lulusan agar memiliki daya saing yang tinggi tidak hanya pada penguasaan bahasa Perancis sebagai bahasa asing (Français Langue Etrangère) atau FLE, tetapi juga difokuskan pada pengenalan terhadap fungsi manajemen dan pemerolehan pengetahuan ekonomi dan bisnis dalam bahasa Perancis sekaligus pemahaman akan budaya frankofon (penutur bahasa Perancis) di bidang bisnis.

Kendala yang dihadapi dalam upaya penyiapan mahasiswa untuk lebih memahami dan menguasai materi bahasa Perancis untuk tujuan khusus adalah belum adanya model pembelajaran di jurusan yang mengemas materi bahasa Perancis di bidang ekonomi dan bisnis. Selain itu, porsi materi untuk pembelajaran bahasa Perancis standar atau bahasa Perancis sebagai bahasa asing $(F L E)$, apabila melihat kurikulum, lebih besar dibandingkan pembelajaran FOS. Hal ini wajar saja sehubungan dengan tujuan utama dari penyelenggaraan pendidikan di jurusan adalah mencetak calon pendidik dan tenaga kependidikan. 
Dengan demikian, hal tersebut menjadi tantangan bagi para pengajar FOS, khususnya pada mata kuliah Français de la Communication Professionnelle yang terkait secara langsung dengan materi bahasa Perancis komunikasi profesional, untuk lebih berupaya mencari dan meneliti berbagai metode dan model pembelajaran dalam rangka pencapaian tujuan pembelajarannya.

Merujuk pada uraian di atas, perlu adanya modifikasi dalam proses pembelajaran pada mata kuliah Français de la Communication Professionnelle di Jurusan Pendidikan Bahsa Perancis FPBS UPI dengan berupaya mengembangkan model pembelajaran komunikasi bisnis. Sekaitan dengan hal itu, tujuan penelitian ini adalah untuk memperoleh data perihal: 1) efektivitas penggunaan model pembelajaran komunikasi bisnis dalam mengembangkan kemampuan mahasiswa untuk memahami konsep-konsep bahasa Perancis komunikasi profesional; 2) kontribusi model komunikasi bisnis dalam pembelajaran Français de la Communication Professionnelle; 3) kelebihan dan kekurangan model komunikasi bisnis dalam pembelajaran Français de la Communication Professionnelle.

\section{METODE}

Pendekatan yang digunakan dalam penelitian ini adalah pendekatan kuantitatif. Pendekatan ini dipilih dikarenakan tujuan penelitian ini adalah untuk memperoleh data perihal keefektifan model komunikasi bisnis, kontribusinya dan kelebihan serta kekurangannya dalam pembelajaran Français de la Communication Professionnelle. Adapun jenis metode penelitiannya yaitu eksperimen semu dengan desain penelitian One Group Time Series Design yang digambarkan sebagai berikut:

\section{T1 T2 T3 X T4 T5 T6}

Keterangan :

T1, T2, T3: Tes yang diberikan sebelum dikenalkan pengajaran (tes awal)

T4, T5, T6: Tes yang diberikan setelah diberikan perlakuan (tes akhir)

$\mathrm{X}$ : Perlakuan yang diberikan beberapa kali

Pada desain penelitian ini, menurut Campbel dan Stanley (Setiyadi, 2006:136139) data yang diperoleh yaitu dengan cara membandingkan mean dari beberapa tes awal (atau frekwensi), dan mean dari beberapa tes akhir tanpa melihat standar deviasinya sehingga hasil analisa datanya digambarkan dengan grafik (garis). Pada desain penelitian di atas, sebetulnya perlakuan diberikan tidak hanya setelah tes awal (digambarkan setelah ' $\mathrm{X}$ '), akan tetapi sebelum diberikan tes awal pun pada dasarnya responden telah diberikan perlakuan (digambarkan dengan ' 0 '). Sehingga desain penelitian di atas dapat diperjelas dengan gambar berikut:

\section{T1 0 T2 0 T3 X T4 X T5 X T6}

Dalam pelaksanaannya, tes awal dilakukan sebanyak tiga kali untuk memperoleh rata-rata nilai (mean) dan dilakukan dengan cara memberikan pembelajaran (perlakuan) terkait materi awal komunikasi bisnis dan selanjutnya mahasiswa (responden) diberikan soal tes awal yang dijawab berdasarkan hasil pemahaman mereka terkait materi tersebut. Selanjutnya, setelah dilakukan tes awal sebanyak tiga kali, mahasiswa kembali diberi perlakuan berupa pemberian materi lain terkait komunikasi bisnis dan kemudian diberikan tes akhir sebanyak tiga kali untuk mengukur pemahaman dan penguasaan mereka terkait materi tersebut.

Populasi pada penelitian ini adalah keseluruhan subjek penelitian, yaitu karakteristik keterampilan mahasiswa semester V Jurusan Pendidikan Bahasa Perancis FPBS Universitas Pendidikan Indonesia. Sedangkan yang dijadikan sampel dalam penelitian ini adalah seluruh nilai tes awal dan nilai tes akhir mahasiswa 
semester V kelas B Jurusan Pendidikan Bahasa Perancis FPBS UPI tahun akademik 2010/2011 yang sedang mengikuti perkuliahan Français de la Communication Professionnelle.

\section{HASIL DAN PEMBAHASAN}

Dalam penelitian ini, model yang dikembangkan yaitu model komunikasi bisnis frankofon berawal dari kumpulan bahan seminar dalam Documents pédagogiques du français de la communication professionnelle yang ditulis pada tahun 2007 oleh Michel Danilo yang telah tim peneliti padukan dengan teori lain yang diperoleh dari laman (http://www.eslgold.com) terkait tips for teaching business english. Dalam model komunikasi bisnis frankofon ini, terdapat tiga hal yang mesti diajarkan pada pembelajar bahasa Perancis untuk Tujuan Khusus, yaitu: 1) Bahasa bisnis (langues d'affaires) yang terfokus pada pengajaran kosakata dan kalimat yang digunakan dalam dunia bisnis dengan memperhatikan jenis bahan yang disajikan (baik teks atau artikel bisnis); 2) Interaksi bisnis (Interaction d'affaires) yang mengarah pada pengenalan terhadap dokumen terkait strategi negosiasi, meyakinkan partner bisnis, menyampaikan suatu informasi tertulis, dan lain-lain, serta; 3) Korespondensi bisnis (correspondances dans les affaires) yang diarahkan pada penguasaan penulisan dokumen bisnis di antaranya pemahaman yang berhubungan dengan proses perekrutan pegawai (recrutement d'employé), menulis surat lamaran kerja (lettre de motivation) dan menulis riwayat hidup (curriculum vitae).

Sekaitan dengan teori yang dikemukakan oleh Kemp dalam Cahyani (2008:5), tentang proses penyusunan model pembelajaran, model komunikasi bisnis yang diterapkan dalam pembelajaran Français de la Communication Professionnelle melalui 10 tahapan sebagai berikut: a. Melakukan assesment kebutuhan belajar, merumuskan tujuan, mengidentifikasi hambatan, dan menetapkan prioritas yang akan digunakan untuk pengorganisasian program pengajaran bahasa Perancis komunikasi profesional.

b. Memilih pokok bahasan dan/atau tugastugas yang harus dilakukan dalam pengajaran serta menemukan indikator pencapaian tujuan pengajaran.

c. Mengenali dan mengkaji karakteristik publik pembelajar dalam hal ini mahasiswa terkait motivasinya dalam mempelajari FOS untuk dijadikan masukan dalam perencanaan dan pelaksanaan pembelajaran.

d. Mengidentifikasi isi/materi atau bahan pelajaran dan/atau menganalisis rincian tugas yang berkaitan dengan pencapaian tujuan umum pengajaran.

e. Merumuskan tujuan belajar yang harus dicapai oleh mahasiswa sesuai dengan isi/materi pelajaran dan/atau rincian tugas.

f. Merancang kegiatan pembelajaran untuk mencapai tujuan belajar yang telah ditetapkan.

g. Memilih alat-alat bantu untuk mendukung kegiatan pembelajaran.

h. Menentukan fasilitas dan sumbersumber lain yang diperlukan untuk pelaksanaan kegiatan pembelajaran dan untuk pengadaan bahan pelajaran yang akan diajarkan.

i. Mempersiapkan evaluasi proses dan hasil kegiatan pembelajaran.

j. Mempersiapkan dan mengadakan tes bagi mahasiswa untuk mengetahui penguasaan bahan yang telah dipelajari.

Langkah-langkah pelaksanaan pengajaran model komunikasi bisnis frankofon dalam pembelajaran Français de la communication professionnelle adalah sebagai berikut:

1. Pengajar menyiapkan dan membagikan materi berupa fotocopy atau dokumen bisnis kepada mahasiswa.

2. Selanjutnya pengajar meminta mahasiswa untuk menganalisis materi tersebut dengan saksama. 
3. Pengajar meminta mahasiswa untuk mempelajari kosakata dan menganalisis pola kalimatnya.

4. Pengajar meminta mahasiswa untuk mencoba menjelaskan materi atau dokumen dimaksud sesuai dengan hasil analisisnya.

5. Pengajar mengajukan pertanyaan untuk memancing reaksi mahasiswa. Berikut contoh pertanyaan yang diajukan:

- A votre avis, qui est l'émetteur de ce document/ de ce message?

- Qui est le récepteur de ce document?

- Quel type de communication s'agit-il?

- Quels sont les objectifs de ce document/ de ce message?

- Quel type de média utilisé par l'émetteur?

- Pourquoi transmet-il ce message?

- Etc.

5. Setelah itu, pengajar meminta mahasiswa untuk kembali menganalisis materi yang diberikan dengan cara mengidentifikasi dan mencari informasi tentang asal atau sumber dokumen, publik yang dituju dan unsur kebahasaannya (unsur tata bahasa dan leksikal), tentang pengirim pesan, dan jenis dokumen yang dibuat.

6. Pengajar selanjutnya meminta mahasiswa untuk memperhatikan dan mencatat unsur pembentuk komunikasi yaitu: 1) komunikator $=$ who (communicator, source, sender); 2) pesan = says what (message); 3) media = in which channel (channel, media); 4) komunikan $=$ to whom (communicant, communicatee, reciever, recipient); 5) efek (effect, impact, influence).

7. Pengajar membagi mahasiswa menjadi beberapa kelompok dan selanjutnya memandu jalannya diskusi kelompok membahas hasil pekerjaan mereka.

8. Pengajar melakukan evaluasi proses melalui kegiatan diskusi hasil analisis mahasiswa terhadap materi atau dokumen yang dipelajari.

9. Pengajar membahas hasil kajian mahasiswa dan menjawab kesulitan yang dihadapi oleh mahasiswa.

10. Pengajar melaksanakan tes bagi mahasiswa untuk mengetahui pemahaman dan penguasaan bahan atau materi yang telah dipelajari.

Adapun rincian tahap - tahap pemberian materi adalah sebagai berikut:

1. Pada pertemuan pertama, mahasiswa diberikan pengajaran terkait materi pertama yaitu: 1) Notions de base de l'information et de la communication; 2) Notions de la communication professionnelle; 3) Notions de la communication d'affaires. Kemudian mahasiswa diberi tes awal pertama (T1) untuk mengetahui pemahaman dan kemampuan mereka terkait materi yang diberikan.

2. Pada pertemuan kedua, mahasiswa diberikan pengajaran terkait materi selanjutnya, yaitu: 1) Notions de l'entreprise et son organisation; 2) Agents économiques et leurs opérations ; 3) Activité d'échange de l'entreprise. Kemudian mahasiswa diberi tes awal kedua (T2) untuk mengetahui pemahaman dan kemampuan mereka terkait materi yang diberikan.

3. Pada pertemuan ketiga, mahasiswa diberikan pengajaran terkait materi 
selanjutnya, yaitu: 1) Objectifs de la communication dans l'entreprise; 2) Situations de communication professionnelle 3) Communiquer dans l'entreprise. Kemudian mahasiswa diberi tes awal ketiga (T3) untuk mengetahui pemahaman dan kemampuan mereka terkait materi yang diberikan.

4. Pada pertemuan keempat, mahasiswa diberikan pengajaran terkait materi selanjutnya, yaitu: 1) Communication interne (à l'oral et à l'écrit); 2) Analyse des documents professionnels (procès verbal, note de service, compte-rendu, rapport). Kemudian mahasiswa diberi tes akhir berupa tes keempat (T4) dari rangkaian waktu (time series) sebelumnya dengan tujuan untuk mengetahui pemahaman dan kemampuan mereka terkait materi yang diberikan.

5. Pada pertemuan kelima, mahasiswa diberikan pengajaran terkait materi selanjutnya, yaitu: 1) Analyse des petites annonces; 2) Analyse des annonces d'offre d'emploi. Kemudian mahasiswa diberi tes akhir berupa tes kelima (T5) dari rangkaian waktu sebelumnya dengan tujuan untuk mengetahui pemahaman dan kemampuan mereka terkait materi yang diberikan.

6. Pada pertemuan keenam, mahasiswa diberikan pengajaran terkait materi selanjutnya, yaitu: 1) Opération de recrutement d'employé; 2) Étapes de recrutement d'employé, dan; 3) rédaction d'une lettre de motivation et d'un curriculum vitae. Kemudian mahasiswa diberi tes akhir berupa tes keenam (T6) dari rangkaian waktu sebelumnya dengan tujuan untuk mengetahui pemahaman dan kemampuan mereka terkait materi yang diberikan.

Untuk memperoleh data dilakukan tes awal sebanyak tiga kali dengan maksud mencari nilai rata-rata (mean). Jumlah soal tes awal yang diberikan kepada mahasiswa beragam tetapi nilai keseluruhan dari tes tersebut adalah 40. Dengan demikian nilai ideal yang diperoleh mahasiswa apabila semua jawabannya benar adalah 40 . Berikut ini daftar distribusi nilai tes awal: 
Tabel 1. Distribusi Nilai Tes Awal

\begin{tabular}{|c|c|c|c|c|c|}
\hline \multirow[t]{2}{*}{ No. } & \multirow{2}{*}{$\begin{array}{c}\text { NIM } \\
\text { Responden }\end{array}$} & \multicolumn{3}{|c|}{ Total Nilai/ 40} & \multirow{2}{*}{$\begin{array}{c}\text { Nilai Rata- } \\
\text { Rata } \\
\text { (M) }\end{array}$} \\
\hline & & $\mathbf{X 1}$ & $\mathbf{X} 2$ & $\mathbf{X ~ 3}$ & \\
\hline 1. & 0800466 & 18 & 21 & 27 & 22 \\
\hline 2. & 0800473 & 15 & 19 & 22 & 18,67 \\
\hline 3. & 0800484 & 19 & 18 & 26 & 21 \\
\hline 4. & 0800655 & 18 & 22 & 32 & 24 \\
\hline 5. & 0800769 & 22 & 26 & 30 & 26 \\
\hline 6. & 0802528 & 18 & 22 & 18 & 19,33 \\
\hline 7. & 0803074 & 20 & 28 & 26 & 24,67 \\
\hline 8. & 0807448 & 22 & 24 & 30 & 25,55 \\
\hline 9. & 0807452 & 15 & 18 & 26 & 19,67 \\
\hline 10. & 0807453 & 25 & 32 & 30 & 29 \\
\hline 11. & 0808493 & 20 & 26 & 34 & 26,67 \\
\hline 12. & 0808495 & 20 & 18 & 24 & 20,67 \\
\hline 13. & 0808721 & 18 & 28 & 26 & 24 \\
\hline 14. & 0808983 & 24 & 26 & 30 & 26,67 \\
\hline 15. & 0809055 & 22 & 18 & 26 & 22 \\
\hline 16. & 0809056 & 22 & 32 & 28 & 27,33 \\
\hline 17. & 0809057 & 20 & 28 & 30 & 26 \\
\hline 18. & 0809058 & 25 & 32 & 26 & 27,67 \\
\hline 19. & 0809059 & 18 & 20 & 28 & 22 \\
\hline 20. & 0809562 & 22 & 26 & 20 & 22,67 \\
\hline 21. & 0800069 & 32 & 26 & 30 & 29,33 \\
\hline 22. & 0800080 & 28 & 26 & 22 & 25,33 \\
\hline 23. & 0800695 & 20 & 32 & 28 & 26,67 \\
\hline 24. & 0801234 & 20 & 26 & 32 & 26 \\
\hline 25. & 0804180 & 25 & 30 & 32 & 29 \\
\hline 26. & 0804625 & 18 & 26 & 24 & 22,67 \\
\hline 27. & 0807438 & 22 & 18 & 20 & 20 \\
\hline 28. & 0807442 & 22 & 18 & 26 & 22 \\
\hline 29. & 0807445 & 28 & 24 & 30 & 27,33 \\
\hline 30. & 0807447 & 32 & 26 & 32 & 30 \\
\hline$\sum \mathrm{N}=30$ & & $\sum X 1=650$ & $\sum X 2=736$ & $\sum X 3=815$ & $\sum \mathrm{M}=733,68$ \\
\hline
\end{tabular}

Berdasarkan distribusi nilai tes awal di atas, diperoleh data kemampuan mahasiswa cukup beragam. Terdapat 12 responden yang memperoleh rata-rata nilai yang kurang baik (kurang dari 24 dari total nilai 40) yaitu responden nomor $1,2,3,6,9,12,15,19,20,26,27, \quad$ dan 28 . Adapun mahasiswa yang memiliki nilai baik (lebih dari 28 dari total nilai 40) berjumlah 4 orang yaitu responden dengan nomor $10,21,25$, dan 30 . Sisanya memiliki nilai yang sedang yaitu antara 24 hingga 27 berjumlah 14 orang.
Sedangkan untuk tes akhir dilakukan sebanyak tiga kali dengan tujuan seperti halnya tes awal yaitu untuk memperoleh nilai rata-rata (mean). Jumlah soal tes awal yang diberikan kepada mahasiswa beragam tetapi nilai keseluruhan (total nilai) dari tes tersebut adalah 40. Dengan demikian nilai ideal yang diperoleh mahasiswa apabila semua jawabannya benar adalah 40. Berikut ini daftar distribusi nilai tes akhir: 
Tabel 2. Distribusi Nilai Tes Akhir

\begin{tabular}{|c|c|c|c|c|c|}
\hline \multirow[t]{2}{*}{ No. } & \multirow{2}{*}{$\begin{array}{c}\text { NIM } \\
\text { Responden }\end{array}$} & \multicolumn{3}{|c|}{ Total Nilai/ 40} & \multirow{2}{*}{$\begin{array}{c}\text { Nilai Rata- } \\
\text { Rata } \\
\text { (M) }\end{array}$} \\
\hline & & $\mathbf{X} 4$ & X 5 & X 6 & \\
\hline 1. & 0800466 & 26 & 32 & 36 & 31,33 \\
\hline 2. & 0800473 & 30 & 28 & 34 & 30,67 \\
\hline 3. & 0800484 & 28 & 34 & 30 & 30,67 \\
\hline 4. & 0800655 & 28 & 30 & 32 & 30 \\
\hline 5. & 0800769 & 26 & 28 & 32 & 28,67 \\
\hline 6. & 0802528 & 22 & 27 & 34 & 27,67 \\
\hline 7. & 0803074 & 36 & 32 & 30 & 32,67 \\
\hline 8. & 0807448 & 32 & 28 & 32 & 30,67 \\
\hline 9. & 0807452 & 30 & 34 & 32 & 32 \\
\hline 10. & 0807453 & 28 & 30 & 28 & 28,67 \\
\hline 11. & 0808493 & 32 & 30 & 32 & 31,33 \\
\hline 12. & 0808495 & 30 & 28 & 30 & 29,33 \\
\hline 13. & 0808721 & 24 & 30 & 32 & 28,67 \\
\hline 14. & 0808983 & 24 & 28 & 30 & 30,67 \\
\hline 15. & 0809055 & 30 & 32 & 28 & 30 \\
\hline 16. & 0809056 & 28 & 32 & 30 & 30 \\
\hline 17. & 0809057 & 32 & 26 & 32 & 30 \\
\hline 18. & 0809058 & 32 & 30 & 28 & 30 \\
\hline 19. & 0809059 & 30 & 26 & 34 & 30 \\
\hline 20. & 0809562 & 28 & 26 & 32 & 28,67 \\
\hline 21. & 0800069 & 32 & 34 & 30 & 32 \\
\hline 22. & 0800080 & 30 & 28 & 32 & 30,67 \\
\hline 23. & 0800695 & 32 & 28 & 34 & 31,33 \\
\hline 24. & 0801234 & 30 & 30 & 28 & 29,33 \\
\hline 25. & 0804180 & 34 & 32 & 28 & 31,33 \\
\hline 26. & 0804625 & 28 & 30 & 32 & 30 \\
\hline 27. & 0807438 & 28 & 28 & 32 & 29,33 \\
\hline 28. & 0807442 & 30 & 28 & 34 & 30,67 \\
\hline 29. & 0807445 & 26 & 28 & 32 & 28,67 \\
\hline 30. & 0807447 & 28 & 32 & 30 & 30 \\
\hline$\sum \mathrm{N}=30$ & & $\sum X 4=884$ & $\sum X 5=889$ & $\sum X 6=940$ & $\sum \mathrm{M}=905,02$ \\
\hline
\end{tabular}

Berdasarkan data distribusi nilai tes akhir di atas, diketahui bahwa kemampuan mahasiswa meningkat. Hal ini terlihat dari perolehan nilai rata-rata terkecil yaitu 27,67 dari total nilai nilai 40 . Terdapat 21 responden yang memperoleh rata-rata nilai yang sangat baik yaitu 30 dari total nilai 40. Sisanya memiliki cukup baik yaitu berjumlah 9 orang.

Analisis data hasil tes awal dan akhir dilakukan untuk menggambarkan grafik (garis) sebagai hasil penelitian dalam rangka memperlihatkan efektivitas model yang diujikan. Untuk itu, terlebih dahulu dihitung nilai rata-rata (mean) dari tiap tes baik untuk tes awal maupun tes akhir.

a) Nilai rata-rata tes awal 1 (X1)

$$
\mathrm{M}=\underline{\Sigma X 1}=\underline{650}=21,67
$$$$
\text { n } 30
$$

b) Nilai rata-rata tes awal 2 (X2)

$\mathrm{M}=\underline{\Sigma \mathrm{X} 2}=\underline{736}=24,53$

$$
\text { n } \quad \frac{736}{30}
$$

c) Nilai rata-rata tes awal 3 (X3)

$$
\mathrm{M}=\frac{\Sigma \mathrm{X} 3}{\mathrm{n}}=\frac{815}{30}=27,17
$$

d) Nilai rata-rata tes akhir 1 (X4)

$$
\mathrm{M}=\frac{\Sigma \mathrm{X} 4}{\mathrm{n}}=\frac{884}{30}=29,47
$$

e) Nilai rata-rata tes akhir 2 (X5) 


$$
\mathrm{M}=\frac{\Sigma X 5}{\mathrm{n}}=\frac{889}{30}=29,63
$$

f) Nilai rata-rata tes akhir 3 (X6)

$$
\mathrm{M}=\frac{\Sigma \mathrm{XX} 6}{\mathrm{n}}=\frac{940}{30}=31,33
$$

Hasil analisis data nilai rata-rata (mean) tes awal dan akhir di atas, dapat diperhatikan bahwa secara umum kemampuan responden (mahasiswa) mengalami peningkatan. Hal ini terlihat dari total rata-rata nilai yang diperoleh yaitu nilai rata-rata tes awal 1 (X1) sejumlah 21,67 , nilai rata-rata tes awal 2 (X2) sejumlah 24,53 , nilai rata-rata tes awal 3 (X3) sejumlah 27,17. Sedangkan nilai rata-rata tes akhir 1 (X4) sejumlah 29,47, nilai rata-rata tes akhir 2 (X5) sejumlah 29,63, nilai rata-rata tes akhir 3 (X6) sejumlah 31,33. Nilai rata-rata tersebut dapat digambarkan melalui grafik berikut.

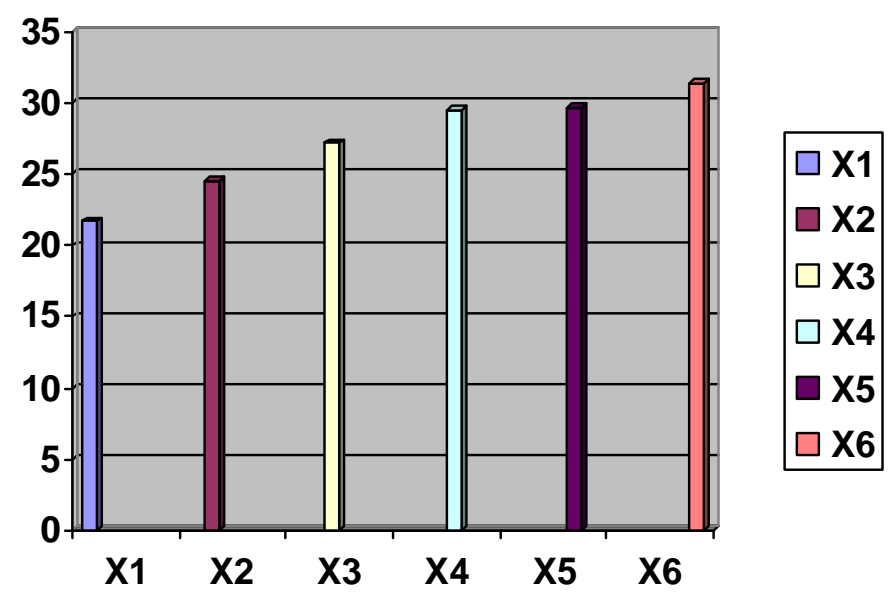

Grafik 1. Nilai rata-rata tes

Berdasarkan pada grafik di atas, dapat disimpulkan bahwa model komunikasi bisnis frankofon dalam pembelajaran Français de la communication professionnelle terbukti efektif dan berkontribusi dalam rangka meningkatkan pemahaman dan kemampuan mahasiswa terhadap konsep dunia bisnis frankofon dan kemampuan menulis dokumen bisnis frankofon yang telah dipelajari.

Mengacu pada hasil dan pembahasan di atas, dapat diketahui bahwa (1) pendekatan model komunikasi bisnis frankofon berkontribusi cukup signifikan dalam proses pembelajaran Français de la communication professionnelle (PR308). Hal ini terbukti dari peningkatan nilai rata- rata (mean) tes awal mahasiswa yaitu nilai rata-rata tes awal 1 (X1) sejumlah 21,67, nilai rata-rata tes awal 2 (X2) sejumlah 24,53, nilai rata-rata tes awal 3 (X3) sejumlah 27,17 . Sedangkan nilai rata-rata tes akhir 1 (X4) sejumlah 29,47, nilai ratarata tes akhir 2 (X5) sejumlah 29,63, nilai rata-rata tes akhir 3 (X6) sejumlah 31,33. Dengan demikian, model komunikasi bisnis frankofon terbukti efektif diterapkan dalam pembelajaran Français de la communication professionnelle. Keefektivan ini ditunjukkan oleh perubahan yang cukup berarti baik dari pihak mahasiswa maupun pengajar. Bagi mahasiswa, mereka dapat melakukan analisis terhadap konsep dan dokumen bisnis frankofon dengan menggunakan 
tahapan yang terdapat pada model komunikasi bisnis frankofon. Begitu pula bagi pengajar, mereka menggunakan cara/metode mengajarnya sesuai dengan prosedur yang semestinya untuk memberikan pengajaran terkait bahasa Perancis untuk dunia bisnis dan profesi dalam upaya pembelajaran bahasa Perancis untuk Tujuan Khusus (Français sur objectifs spécifiques). Perubahan tersebut telah membawa mahasiswa ke arah pencapaian tujuan pembelajaran analisis konsep dan praktek penulisan dokumen bisnis frankofon sebagaimana tercantum dalam silabus mata kuliah Français de la communication professionnelle (PR308);

Di samping berkontribusi positif dan terbukti efektif diterapkan dalam pembelajaran, model komunikasi bisnis frankofon ini pun memiliki kelebihan dan kekurangan. Kelebihannya adalah: 1) dapat memotivasi mahasiswa terkait keinginannya untuk bekerja di luar jalur kependidikan yaitu dunia bisnis dan wirausaha, dikarenakan materi yang dikemas banyak menyentuh kebutuhan sebagai aktor bisnis di antaranya: a) pembelajaran bahasa bisnis (langues d'affaires) yang terfokus pada pengajaran kosakata dan kalimat yang digunakan dalam dunia bisnis dengan memperhatikan jenis bahan yang disajikan (baik teks atau artikel bisnis); b) pembelajaran interaksi dalam berbisnis (Interaction d'affaires) yang mengarah pada pengenalan terhadap dokumen terkait strategi negosiasi, meyakinkan partner bisnis, menyampaikan suatu informasi tertulis, dan lain-lain, serta; c) pengenalan terhadap dokumen di antaranya korespondensi bisnis (correspondance et d'autres documents d'affaires) yang diarahkan pada penguasaan penulisan dokumen bisnis terkait rekrutmen pegawai (recrutement d'employé), surat lamaran kerja (lettre de motivation) dan riwayat hidup (curriculum vitae); 2); model ini pun mampu mengembangkan wawasan keilmuan mahasiswa dan pengajar, terutama dari segi pengayaan teks atau dokumen yang sebelumnya belum pernah diujikan dalam perkuliahan; 3) khusus bagi pengajar, model ini akan lebih menuntut untuk melakukan persiapan yang matang, baik dalam memilih jenis teks atau dokumen maupun kandungan unsur-unsur yang menarik dan perlu untuk dibahas terkait dunia bisnis (le monde d'affaires francophones). Adapun kekurangannya adalah: 1) model ini terlihat sama saja dengan model pembelajaran lainnya, yang membedakan hanyalah penyajian atau kemasan materi yang lebih mengarah pada penguasaan bahasa Perancis bisnis (le français des affaires) bukan bahasa Perancis sebagai bahasa asing (le français langue étrangère); 2) banyaknya bidang kajian bisnis frankofon sehingga model ini tidak dapat mengulas seluruhnya melainkan sebagian materi saja yaitu materi bahasa bisnis (langue d'affaires), interaksi bisnis (interaction d'affaires) dan dokumen bisnis (documents d'affaires).

\section{SIMPULAN DAN SARAN}

Model yang telah diteliti sesuai dengan hasil analisis data telah dapat meningkatkan kemampuan mahasiswa dalam mempelajari bahasa Perancis bisnis frankofon. Oleh karena itu, peneliti menyimpulkan bahwa model tersebut terbukti efektif dan berkontribusi dalam meningkatkan kualitas pembelajaran mata kuliah Français de la communication professionnelle (PR308). Terdapat beberapa hal yang perlu untuk dipertimbangkan untuk perbaikan proses pembelajaran bahasa Perancis untuk Tujuan Khusus mendatang baik kepada pengajar, pembelajar maupun peneliti sejenis lainnya. Bagi pengajar mata kuliah Français de la communication professionnelle (PR308) direkomendasikan untuk dapat menggunakan berbagai alternatif model dan pendekatan, di antaranya model komunikasi bisnis frankofon sebagai upaya memperkenalkan 
konsep bahasa Perancis profesional dan bisnis kepada mahasiswa agar tidak hanya memberikan materi yang menuntut keterampilan berbahasa Perancis tetapi juga materi keprofesian dan bisnis terkait dunia nyata. Bagi peneliti sejenis lainnya, diharapkan hasil penelitian ini dapat dijadikan referensi untuk penelitian selanjutnya dan bila mungkin dikaji dan diteliti kembali sebagai upaya pengembangan keilmuan terkait pembelajaran bahasa Perancis untuk Tujuan Khusus terutama untuk français de la communication professionnelle yang merupakan mata kuliah inisiasi (pengenalan) terhadap bahasa Perancis untuk Tujuan Khusus lainnya seperti français du tourisme, français des affaires, français des médias dan français de l'hôtellerie et de la restauration yang memang berbeda dari pengajaran bahasa Perancis sebagai bahasa asing (Français langue étrangère).

\section{UCAPAN TERIMA KASIH}

Tim peneliti mengucapkan terima kasih kepada pihak Universitas Pendidikan Indonesia melalui LPPM UPI yang telah membantu dalam pendanaan penelitian ini dan kepada Jurusan Pendidikan Bahasa Perancis FPBS UPI seta para mahasiswa sebagai responden penelitian yang telah membantu kelancaran dalam pemerolehan data penelitian ini.

\section{PUSTAKA RUJUKAN}

Cahyani, D, et al. (2008). "Model Pembelajaran Berbicara Berbasis Photo-Expressions pada Mata Kuliah Communication Orale III Jurusan Pendidikan Bahasa Perancis FPBS UPI'. Laporan Penelitian. Tidak diterbitkan.

Eurin, Simone, et al. (1992). Français sur Objectifs Spécifiques. Grenoble: CNED.

Hardini, T.I. (2002). "Penilaian Kemampuan Menulis Mahasiswa dengan Model Writing Workshop melalui internet". Jurnal Bahasa \& Sastra, Vol.6 (1), April hal.46-61.

Mangiante, J-M \& Parpette, C. (2004). Le Français sur Objectifs Spécifiques: de l'Analyse des Besoins à l'Elaboration d'un Cours. Paris : Hachette.

Setiyadi, B. (2006). Metode Penelitian untuk Pengajaran Bahasa Asing; Pendekatan Kuantitatif dan Kualitatif. Yogyakarta: Graha Ilmu.

Tim Penyusun Jurusan. (2009). Revisi Silabus dan SAP Jurusan Pendidikan Bahasa Perancis FPBS UPI.

Zabardi, A. (2004). "Se former au Français sur objectifs spécifique" pada laman: http://www.francparler.org/articles/ zabardi2005.htm.

http://www.eslgold.com/teaching english business 